\title{
Prospective hospital based study on persistent diarrhoea
}

\author{
P Dutta, M Lahiri, D Sen, S C Pal
}

\begin{abstract}
A total of 383 children aged less than 5 years suffering from acute watery diarrhoea or dysentery were studied in hospital to determine the rate of persistent diarrhoea. Altogether 335 $(87.5 \%)$ recovered within 13 days. Only in 48 $(12.5 \%)$ did the diarrhoea continue for 14 days or more, and they were considered as having persistent diarrhoea. Children aged between 7 and 18 months had a significantly increased incidence of persistent diarrhoea. Children suffering from grade II-IV malnutrition constituted the majority $(\mathbf{7 0 . 8 \%})$ of those with persistent diarrhoea. Higher rates of isolation of Shigella flexneri, Shigella dysenteriae 1, and Salmonella typhimurium were observed among patients with persistent diarrhoea than in those with diarrhoea of shorter duration. No positive correlations were observed between the clinical severity of disease at hospital admission and measles. Breast fed babies were not prone to persistent diarrhoea.
\end{abstract}

Diarrhoeal diseases are a major cause of morbidity and mortality, particularly in children in developing countries, and have been extensively studied over the past three decades. Most of the research relates to acute or chronic diarrhoeal illness. Though persistent diarrhoea is an important problem, our understanding of it is still limited.

Persistent diarrhoea has been defined as a diarrhoeal episode of presumed infectious aetiology that begins suddenly and lasts more than 14 days. ${ }^{1}$ It seems to be a separate clinical and epidemiological entity and a battery of risk factors may be associated with this condition. Accurate information regarding its incidence and risk factors should come from prospective community based studies but such studies are few. ${ }^{2-4}$ However, it has been recommended by the Diarrhoeal Diseases Control Programme of the World Health Organisation that hospital based studies of this problem should also be carried out in developing countries. ${ }^{5}$ The present study is an attempt to determine the incidence of persistent diarrhoea and to delineate some of the risk factors associated with it in hospitalised patients.

\section{Methods}

Dr B C Roy Memorial Hospital for Children is the biggest paediatric hospital in Calcutta, providing free treatment to inpatients and outpatients. Patients come from all socioeconomic groups, either directly or after referral from other state hospitals. Approximately 6000 patients with acute watery diarrhoea or dysentery are admitted to the hospital annually and another
7000 to 8000 patients with acute diarrhoea or dysentery receive treatment as outpatients. Patients are treated throughout the year, but most are seen during the hot summer months (April to July) and during the monsoon (August to September). A surveillance system was set up by the National Institute of Cholera and Enteric Diseases to study a representative sample of diarrhoea patients at this hospital.

\section{SUBJECTS}

Children of both sexes up to the age of 5 years, suffering from acute watery diarrhoea or dysentery (blood and mucus in stools) of less than three days' duration, irrespective of severity, and admitted between 8 am and 1 pm during the first four days of the week were studied. Patients with post measles diarrhoea were included.

Patients who had received antibiotics before admission, or those with a history of diarrhoea exceeding three days and those with diarrhoea complicated by systemic illness - for example respiratory tract infection or septicaemia - were excluded.

\section{DEFINITIONS}

Diarrhoea was defined as the passage of three or more loose stools during the preceding 24 hours. In breast fed babies, the mother's perception was considered in defining diarrhoea. Cessation of diarrhoea was defined as the passage of the last loose stool followed by three consecutive days without diarrhoea. Persistent diarrhoea was defined as an episode of diarrhoea lasting for 14 days or more.

\section{CLINICAL EVALUATION}

On hospital admission, a detailed clinical history was obtained and a thorough physical examination was performed. Findings were recorded on a proforma. The severity of watery diarrhoea was assessed by clinical signs and symptoms of dehydration, ${ }^{6}$ whereas dysentery was assessed by frequency of stools per day together with associated symptoms like fever and tenesmus. ${ }^{7}$ Patients were weighed naked, to the nearest $10 \mathrm{~g}$, and were allocated to different 'weight for age' nutritional groups according to the Indian Academy of Paediatrics using Harvard standard weight. ${ }^{8}$ Investigators recorded the following parameters daily: number of stools; consistency; presence of blood and mucus in stool; temperature; presence of abdominal pain; tenesmus; anorexia; vomiting; treatment with drugs or fluid (intravenous, oral or both); and the nature and amount of food given. Children were followed up daily until 
discharged. Usually, WHO guidelines ${ }^{6}$ were followed for the management of diarrhoea in the hospital. Patients with mild to moderately dehydrated watery diarrhoea received standard oral glucose electrolyte solution (WHO formula). Those who were severely dehydrated were treated initially with Ringer's lactate solution followed by oral glucose electrolyte solution. Furazolidone was used in standard doses in selected patients only. Patients with dysentery received furazolidone, cotrimoxazole, or ampicillin and if there was no clinical improvement after 72 hours they were changed to nalidixic acid, in standard doses for five days. Feeding schedules of the children were continued and older children received the full hospital diet after correction of dehydration.

\section{MICROBIOLOGICAL PROCEDURES}

Faecal samples were collected on hospital admission and examined microscopically for the presence of blood and mucus and ova, cysts, and parasites. Samples were also cultured or tested for bacterial and viral enteropathogens using standard techniques. ${ }^{9}$ Further samples were examined from children who suffered persistent diarrhoea.

\section{LACTOSE INTOLERANCE}

Stool samples from the symptomatic children were also screened for lactose intolerance on the 14 th day by heating a measured quantity of centrifuged liquid portion of stool with Benedict's reagent and by estimation of acidic $\mathrm{pH}$ by narrow range $\mathrm{pH}$ paper.

\section{STATISTICAL ANALYSIS}

The $\chi^{2}$ test for significance was used for statistical analysis. Relative risk (RR) was calculated by Mantel and Haenszel method. ${ }^{10}$

\section{Results}

A total of 383 children were studied. Of these, $315(82 \cdot 2 \%)$ had watery diarrhoea and $68(17 \cdot 8 \%)$ had dysentery. A total of $335(87.5 \%)$ recovered within 13 days. In $33(8.6 \%)$ children the diarrhoea continued for 14-20 days and in a further $15(3.9 \%)$ it persisted for over 20 days. In all, $48(12 \cdot 5 \%)$ children were considered to have persistent diarrhoea.

\section{HOST FACTORS}

\section{Age}

Children aged 7 to 18 months had a significantly greater incidence of persistent diarrhoea (Table I). Relative risks (RR) of the two groups of children aged between 7 and 12 months and 13 and 18 months were $2 \cdot 6$ and $3 \cdot 3$, respectively.

\section{Nutritional status}

All children with persistent diarrhoea had some degree of malnutrition (Table II). Children with grades II-IV malnutrition constituted the majority $(70 \cdot 8 \%)$. Correlation of persistent diarrhoea and malnutrition was highly statistically significant $\left(\chi^{2}=61 \cdot 3678, \mathrm{p}<0.000001\right)$.

Character of stool, severity of the disease, and agents When duration of diarrhoea was compared with either of the stool characters it was observed that out of 315 patients with watery diarrhoea only 25 (7.9\%) developed persistent diarrhoea compared with 23 of $68(33 \cdot 8 \%)$ children with dysentery. The difference in the incidences of persistent diarrhoea among those with watery diarrhoea and dysentery was statistically significant $\left(\chi^{2}=31.869, \mathrm{p}<0.0001 ; \mathrm{RR}=5 \cdot 9\right)$. The clinical severity on hospital admission of patients with watery diarrhoea and those with dysentery had no correlation with the development of persistent diarrhoea (Table III). Table IV shows the detection of enteropathogens on admission to hospital. Enteropathogens were isolated from $81 \cdot 2 \%$ of prospective persistent diarrhoea cases and from $57.9 \%$ patients who did not develop persistent diarrhoea. Shigella flexneri, Shigella dysenteriae 1, and Salmonella typhimurium were isolated statistically more often from patients who went on to develop persistent diarrhoea.

\section{Seasonal distribution}

The rate of hospital admission for acute diarrhoea or dysentery patients, particularly for disease caused by bacterial enteropathogens, was higher during hot summer months (April to July), and $38(75 \%)$ patients with persistent diarrhoea were observed during that period.

\section{Food habits}

Investigation of the relation between different feeding patterns and the duration of diarrhoea showed that there were no breast fed babies among the 48 who developed persistent diarrhoea. Of those who developed persistent diarrhoea, $10 \cdot 4 \%$ were bottle fed, $22 \cdot 9 \%$ were cereal fed, and $66 \%$ were eating a mixed diet, whereas

TABLE I Distribution of age in relation to duration of diarrhoea

\begin{tabular}{llll}
\hline & \multicolumn{2}{l}{$N o(\%)$} & \\
\cline { 2 - 4 } $\begin{array}{l}\text { Age group } \\
\text { (mths) }\end{array}$ & $\begin{array}{l}\text { Non-PD } \\
(n=335)\end{array}$ & $\begin{array}{l}P D \\
(n=48)\end{array}$ & $R R$ \\
\hline $0-6$ & $64(19 \cdot 1)$ & 0 & - \\
$7-12$ & $82(24 \cdot 5)$ & $22(45 \cdot 8)$ & $2 \cdot 6^{\star}$ \\
$13-18$ & $60(17 \cdot 9)$ & $20(41 \cdot 7)$ & $3 \cdot 3 \dagger$ \\
$19-24$ & $40(11 \cdot 9)$ & $5(10.4)$ & 0.9 \\
$25-59$ & $89(26 \cdot 6)$ & $1(2 \cdot 1)$ & 0.06 \\
\hline
\end{tabular}

$\mathrm{PD}=$ persistent diarrhoea $; \mathrm{RR}=$ relative risk

$\chi^{i}=8.6305 ; \mathrm{p}=0.003 ;+\chi^{i}=12.937 ; \mathrm{p}=0.0003$.

TABLE II Duration of diarrhoea in relation to nutritional status

\begin{tabular}{lcc}
\hline $\begin{array}{l}\text { Nutritional status } \\
\begin{array}{l}\% \text { Harvard standard } \\
\text { weight for age })\end{array}\end{array}$ & $N o(\%)$ & \\
\cline { 2 - 3 } & Non-PD $(n=335)$ & $P D(n=48)$ \\
\hline $\begin{array}{l}\text { Normal }(>80) \\
\text { Group I malnutrition }\end{array}$ & $\begin{array}{c}78(23 \cdot 3) \\
(71-80)\end{array}$ & $0(0)$ \\
$\begin{array}{l}\text { Groups II-IV } \\
\text { malnutrition }(<70)\end{array}$ & $64(19 \cdot 1)$ & $34(70 \cdot 8)$ \\
\hline
\end{tabular}

$\chi^{:}=61 \cdot 3678 ; p=<0 \cdot 000001 . P D=$ persistent diarrhoea. 
TABLE III Duration of diarrhoea in relation to severity of the diseases

\begin{tabular}{llllll}
\hline & \multicolumn{2}{l}{ Watery diarrhoea $^{\star}(N o(\%))$} & & \multicolumn{2}{l}{ Dysentery $(N o(\%))$} \\
\cline { 2 - 3 } \cline { 5 - 6 } Severity & $N o n-P D(n=290)$ & $P D(n=25)$ & & Non-PD $(n=45)$ & $P D(n=23)$ \\
\hline Mild & $207(71 \cdot 4)$ & $17(68 \cdot 0)$ & & $6(13 \cdot 8)$ & $3(13 \cdot 0)$ \\
Moderate & $62(21 \cdot 4)$ & $6(24 \cdot 0)$ & & $30(66 \cdot 7)$ & $15(65 \cdot 2)$ \\
Severe & $21(7 \cdot 2)$ & $2(8 \cdot 0)$ & & $9(20 \cdot 0)$ & $5(21 \cdot 7)$ \\
\hline
\end{tabular}

${ }^{\star} \chi^{2}=0.1283 ; \mathrm{p}=0.94 ;+\chi^{2}=0.028 ; \mathrm{p}=0.99$. $\mathrm{PD}=$ persistent diarrhoea.

TABLE IV Enteropathogens detected initially in persistent diarrhoea $(P D)$ and non-PD cases

\begin{tabular}{lcc}
\hline & \multicolumn{2}{l}{$N o(\%)$} \\
\cline { 2 - 3 } & $\begin{array}{l}\text { Non-PD } \\
(n=335)\end{array}$ & $\begin{array}{l}\text { Prospective PD } \\
(n=48)\end{array}$ \\
Enteropathogen detected & $33(9 \cdot 9)$ & $4(8 \cdot 3)$ \\
Enteropathogenic Escherichia & & \\
coli & $31(9 \cdot 3)$ & $0(0)$ \\
Rotavirus & $28(8 \cdot 4)$ & $0(0)$ \\
Vibrio cholerae & $16(4 \cdot 8)$ & $13(27 \cdot 1)$ \\
Shigella flexneri & $14(4 \cdot 2)$ & $0(0)$ \\
Campylobacter jejuni & $13(3 \cdot 9)$ & $3(6 \cdot 3)$ \\
Aeromonas sp & $8(2 \cdot 4)$ & $8(16 \cdot 7)$ \\
Salmonella typhimurium & $7(2 \cdot 1)$ & $10(20 \cdot 8)$ \\
S dysenteriae 1 & $5(1 \cdot 5)$ & $0(0)$ \\
Cryptosporidium & $1(0 \cdot 3)$ & $0(0)$ \\
Clostridium difficile & $1(0 \cdot 3)$ & $0(0)$ \\
Entamoeba histolytica & $1(0 \cdot 3)$ & $0(0)$ \\
Giardia lamblia & $36(10 \cdot 7)$ & $1(2 \cdot 1)$ \\
Enteropathogens in & & $39(81 \cdot 3)$ \\
combination & $194(57 \cdot 9)$ & \\
Total & & \\
\hline
\end{tabular}

in children without persistent diarrhoea, $17 \cdot 3 \%$ were bottle fed, $17 \cdot 7 \%$ were cereal fed, $40 \cdot 6 \%$ had mixed feeding, and $23.5 \%$ were breast fed. It was clear that breast fed babies were not prone to persistent diarrhoea compared with the others. No significant differences were observed, however, among the persistent and non-persistent diarrhoea babies who were bottle fed, cereal fed, or had mixed feeding.

\section{Measles}

Fourteen children with post measles diarrhoea and 64 with a history of measles within six months of admission were included in the study but all recovered within 13 days. No significant association between persistent diarrhoea and measles was observed.

Stool samples of 48 children with persistent diarrhoea were re-examined on the 14th day, but none was found to be either positive for any known enteropathogen or showed any evidence of lactose intolerance.

\section{Discussion}

The present study showed an incidence of persistent diarrhoea of $12.5 \%$ in children admitted to hospital. In this study most $(87.5 \%)$ children suffering from persistent diarrhoea were aged between 7 and 18 months. This is in contrast to the progressive rise in incidence with increasing age observed in a community based study in Bangladesh. ${ }^{2}$ In another study in rural India, however, the peak incidence of persistent diarrhoea occurred in children aged between 3 and 5 months. ${ }^{4}$ In the present study, persistent diarrhoea was conspicuously absent in children below 6 months of age, which may reflect the universal practice of breast feeding in this age group. ${ }^{112}$
As in previous reports, ${ }^{1314}$ our study also indicated that malnutrition may be one of the precipitating factors in persistent diarrhoea. The higher incidence of persistent diarrhoea among malnourished children may possibly be the result of depressed immunity ${ }^{15}$ and delayed recovery of intestinal mucosal injury after acute infection, ${ }^{16}$ especially infection caused by enteroinvasive pathogens. In developing countries many children become malnourished just after weaning, because of a lack of an adequate or balanced diet. Furthermore, this is also the age when the risk of infection, particularly diarrhoea, is highest because of greater exposure via contaminated food, drinks, or even environment and lack of the protection probably provided by the breast milk. ${ }^{12}$ It is also quite clear that frequent infections lead to malnutrition ${ }^{17}$ and the high incidence of persistent diarrhoea among children older than 6 months of age could be a reflection of this.

It is well known that certain bacterial and viral infections, including measles, can depress the systemic cell mediated immunity, at least for a time. Some workers ${ }^{18}$ have observed prolonged diarrhoea as a result of this but no such association was observed in the present study.

Regarding aetiological agents, it has been shown that most of the enteropathogens can cause acute as well as persistent diarrhoea except Vibrio cholerae. Increased rates of isolation of enteroinvasive organisms like $S$ dysenteriae type 1,S flexneri, and $S$ typhimurium were noticed during the initial period of illness of the children with persistent diarrhoea in our study, which confirm the findings of a study from Bangladesh. ${ }^{2}$ It has also been reported that aggregative Escherichia coli may be responsible for persistent diarrhoea. ${ }^{19}$ In our study, the severity of both watery diarrhoea and dysentery did not correlate with subsequent delayed recovery, which corroborates other studies. ${ }^{2021}$ Diet has been proposed as a risk factor for persistent diarrhoea ${ }^{22}$ because of changes it can cause to the intestinal microenvironment. None of the breast fed babies in our study suffered from persistent diarrhoea, although other dietary habits (bottle, cereal, and mixed feeding) did not seem to correlate significantly with the occurrence of persistent diarrhoea.

The authors thank the superintendent and visiting physicians of Dr B C Roy Memorial Hospital for Children, Calcutta for allowing us to study patients admitted under them. The authors also thank us to study patients admitted under them. The authors also thank
Drs S K Bhattacharya, D Dutta, U Mitra, M K Bhattacharya,
R Rasaily, S P De, M R Saha, G B Nair, P Das, S K Niyogi, and Mr $\mathrm{R}$ Rasaily, S P De, M R Saha, G B Nair, P Das, S K Niyogi, and Mr
S N Sikdar for their valuable help during the study. The secretarial $\mathrm{S} N$ Sikdar for their valuable help during the stud
help of $\mathrm{Mr} \mathrm{S}$ Karmakar is also acknowledged.

The paper was presented in the Indo-UK Workshop on The paper was presented in the Indo-UK Workshop on
Diarrhoeal Diseases and an abstract of the paper was published in the proceedings of the workshop.

1 World Health Organisation. Persistent diarrhoea in children in developing countries. Geneva: WHO 1988; TAG: 27

2 Black RE, Brown KH, Becker S, Abdul Alim ARM, Huq I. Longitudinal studies of infectious diseases and physical growth of children in rural Bangladesh. II. Incidence of diarrhoea and associated with known pathogen. Am Epidemiol 1982; 115: 312-24.

3 McAuliffe FJ, Shields DS, Auxiliadora M, Sakell J, Schorting J, Guerrant RL. Prolonged and recurring diarrhoea in the , Guerrant Rrazil: Examination of cases from a community northeast of Brazil: Examination of cases from a community Bhan MK, Bhandari N, Sazawal S, et al. Descriptive epihan MK, Bhandari N, Sazawal S, et al. Descriptive epidemiology of persistent diarrhoea among young children in rural nort $281-8$.

5 World Health Organisation. Persistent diarrhoea in children research priorities. Geneva: WHO 1985; TAG: 85.8 
6 World Health Organisation. Manual for the treatment of acute diarrhoea. Geneva: WHO 1984; CDD/SER/80.2 Rev.

7 Bhattacharya SK, Dutta P, Dutta D, et al. Relative efficacy of trimethoprim-sulphamethoxazole and nalidixic acid for acute invasive diarrhoea. Antimicrob Agents Chemother 1987; 31: 837 .

8 Ghai OP. Essential paediatrics. New Delhi: Interprint, 1988.

9 World Health Organisation. Manual for laboratory investigation of acute enteric infections. Geneva: WHO, 1983; CDD/83.3.

10 Armitage P. Statistical methods in medical research. Oxford: Blackwell Scientific Publications, 1974

11 Khin MU, Nyunt NW, Myo K, Mumu K, Tin U, Thane T. Effect of clinical outcome of breast feeding during acute diarrhoea. $B M F$ 1985; 290: 587-9.

12 Kovar MG, Sardula MK, Marks JS, Fraser DW. Review of epidemiological evidence for an association between infant feeding and infant health. Paediatrics 1984; 74: 616-38.

13 Chen LC, Huq E, Haffman SL. A prospective study of risk of diarrhoeal diseases according to nutritional status of the children. Am $\mathcal{F}$ Epidemiol 1981; 114: 284-92.

14 Black RE, Brown KH, Becker S. Malnutrition is a determining factor in diarrhoeal duration but not incidence, among factor in diarrhoeal duration but not incidence, among
children in a longitudinal study in Bangladesh. Am $\mathcal{F}$ Clin
Nutr 1984; 37: 87-94

15 Schlesinger D, Stekel A. Impaired cellular immunity in marasmic infants. Am $\mathcal{F}$ Clin Nutr 1984; 37: 615-20.

16 Brunser O, Reid A, Monckeberg F, et al. Jejunal mucosa in infant malnutrition. Am $\mathcal{F}$ Clin Nutr 1968; 21: 976-83.

17 Sepulveda J, Willett W, Munoz A. Malnutrition and diarrhoea. A longitudinal study among urban Mexican children. rhoea. A longitudinal study among

18 Koster FT, Curlin GC, Aziz KMA, Haque A. Synergistic impact of measles and diarrhoea on nutrition and mortality in Bangladesh. Bull World Health Organ 1981; 59: 901-8.

19 Bhan MK, Sazawal S, Raj P, et al. Aggregative Escherichia coli, Salmonella and Shigella are associated with increasing duration of diarrhoea. Indian $\mathcal{F}$ Paediatr 1989; 56: 81-6.

20 Gribbin M, Walker Smith J, Wood C. Delayed recovery following acute gastroenteritis. Acta Paediatr Belgica 1976; 29: $167-76$.

21 Gribbin M, Walker Smith J, Wood C. A twelve month prospective survey of admissions to the gastroenteritis unit of a children's hospital. Acta Paediatr Belgica 1976; 29: 6977.

22 Cook GC. Causes and control of chronic diarrhoea. Diarrhoea Dialogue 1982; 10: 4-5. 